\title{
Participation of antigens related to the psoriasis associated antigen, pso p27, in immune complex formation in patients with ankylosing spondylitis
}

\author{
EYVIND RØDAHL, KJETIL ASBAKK, AND OLE-JAN IVERSEN
}

From the Department of Microbiology, Faculty of Medicine, University of Trondheim, N-7006 Trondheim, Norway

SUMMARY Analysis of five serum samples and three synovial fluids from patients with ankylosing spondylitis (AS) and five serum samples from healthy blood donors for the presence of antibodies cross reacting with the Fc part of rabbit IgG (rheumatoid factors (RFs)) using an isotype specific, enzyme linked immunosorbent assay (ELISA) showed only insignificant amounts of free RFs, while IgG RFs were observed in alkaline dissociated circulating immune complexes (CICs). Only insignificant amounts of free antibodies reacting with the psoriasis associated antigen pso p27 could be detected in the samples, while extensive amounts of IgG antibodies and moderate amounts of IgM antibodies reacting with pso p27 were detected in alkaline dissociated CICs from the patients. Pso p27 has been reported to share a common determinant with the Fc part of human IgG. Removal of the RF activity from the CICs of patients with AS by absorption with IgG resulted in a decrease of the anti-pso p27 activity. Monoclonal anti-pso p27 antibodies in a sandwich ELISA were used to detect antigens cross reacting with pso p27. A positive reaction was observed in all serum CICs and in one of the synovial fluid CICs. The data indicate that antigens related to pso p27 participate in CIC formation in AS and may also be responsible for the elicitation of rheumatoid factors in patients with AS.

Key words: enzyme linked immunosorbent assay (ELISA), aetiology, retrovirus-like, rheumatoid factor.

Ankylosing spondylitis (AS) is a disorder of unknown aetiology characterised by proliferation of synovial cells and chronic inflammation of joint structures, particularly of the vertebral column. A chronic inflammatory reaction is also observed at the insertions of various tendons and ligaments (enthesopathy). ${ }^{1}$

Cellular proliferation and chronic inflammation are characteristic features of several retrovirus induced disorders. ${ }^{2}$ Retroviruses both of exogenous and endogenous origin may participate in the pathogenesis of chronic arthritis in animals. ${ }^{34}$

Circulating immune complexes (CICs) are frequently observed in animals persistently infected with viruses. ${ }^{5-7} \mathrm{CICs}$ have also been isolated from

Accepted for publication 8 December 1987

Correspondence to Dr Eyvind Rødahl, Department of Microbiology, University Hospital, N-7006 Trondheim. Norway. humans with viral arthritis, ${ }^{89}$ and virus or virus antigens have been shown to participate in CIC

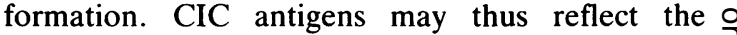
pathogenetic agents causing the disease.

Psoriatic arthritis and AS are closely related disorders and may represent facets of the same syndrome. ${ }^{10} 11$ Genes predisposing to psoriasis may o confer susceptibility both to peripheral arthritis and $N$ to AS and may also modify the clinical course of $\underset{\mathrm{\omega}}{N}$ AS. ${ }^{12} 13$

In a series of papers we have described the isolation of a virus-like particle from a patient with psoriasis. ${ }^{14} 15$ The particle has a buoyant density in $\stackrel{?}{?}$ sucrose and a protein composition closely resemb- $T$ ling that of mammalian retroviruses. The major $\overrightarrow{0}$ internal protein, p27, of the particle (pso p27) has been shown to participate in immune complex formation both in psoriatic scales and in CICs from patients with psoriatic arthritis. ${ }^{16}$ Psoriatic scale has 
recently been shown to represent a convenient source for the isolation of pso p27 (O-J Iversen, K Åsbakk, unpublished data).

Using antiserum against pso p27 in an immunofluorescence analysis, we have previously observed cross-reacting antigens in lymphocytes and mononuclear synovial cells from patients with $\mathrm{AS} .^{17}$

Recently, we have also shown that pso p27 shares a common antigenic determinant with the Fc part of IgG and suggested a role for pso p27 in the development of rheumatoid factors (O-J Iversen et al unpublished data).

In this paper we have analysed CICs from patients with AS for the presence of antibodies reacting with pso p27, and antigens related to pso p27. The samples were also analysed for the presence of antirabbit Fc antibodies.

\section{Patients and methods}

CLINICAL SPECIMENS

Serum samples were obtained from five patients, and knee joint synovial fluid from three patients with AS. In one case (patient No 1) both serum and synovial fluid were obtained from the same patient. All patients were HLA-B27 positive and fulfilled the New York criteria for AS. In addition, serum samples were obtained from five healthy persons.

ISOLATION OF IMMUNE COMPLEXES Immune complexes were isolated by isopycnic ultracentrifugation in $20-65 \%(w / w)$ sucrose gradients. ${ }^{18}$ After dialysis against saline the complexes were dissociated by adjusting the $\mathrm{pH}$ to 10.8 with $0.2 \mathrm{M} \mathrm{NaOH}$.

PSO P27 ANTIGEN

Pso p27 was isolated from psoriatic scales by immunosorbent chromatography, followed by gel filtration on a Sephacryl S-300 column in $6 \mathbf{M}$ guanidine hydrochloride. ${ }^{19}$

MONOCLONAL ANTI-PSO P27 ANTIBODIES

The procedure has been presented in detail elsewhere. ${ }^{19}$ Briefly, BALB/c mice were immunised with purified pso p27. Spleen cells were fused with the myeloma cell line Sp2/0-Ag-14 (Flow Laboratories). Hybrid cells were selected by cultivation in hypoxanthine, aminopterin, thymidine medium. Culture supernatants were assayed for the presence of antibodies reacting with pso p27 and psoriatic blood lymphocytes. Positive cultures were cloned and recloned by limiting dilution. Ascites fluids were obtained after intraperitoneal injection of hybridoma cells into syngeneic mice (BALB/c) None of the antibodies applied in this investigation showed any cross reaction with human IgG.
B I O T IN Y L A T ION

Immunoglobulins were purified from ascites fluid and biotinylated. ${ }^{19}$

\section{MEASUREMENT OF HUMAN}

I M M U NOG L OB U L IN S

The amount of $\operatorname{IgG}, \operatorname{IgA}$, and $\operatorname{IgM}$ in serum, synovial fluid, or immune complex preparations was determined by a sandwich enzyme linked immunosorbent assay (ELISA). ${ }^{20}$ Polystyrene microtitre plates (Linbro 76-381-04, Flow Laboratories) were coated with rabbit antibodies against human IgG, IgA, or IgM (Behringwerke). The assays for the respective isotypes were performed with serum samples diluted $1: 10^{-7}, 1: 10^{-6}$, and $1: 10^{-5}$, synovial fluids diluted $1: 10^{-6}, 1: 10^{-5}$, and $1: 10^{-4}$, and CIC preparations diluted $1: 10^{-3}, 1: 10^{-2}$, and $1: 10^{-2}$ in phosphate buffered saline $\mathrm{pH} 7 \cdot 2$ containing $0.05 \%$ Tween 20 (PBS T20). Bound immunoglobulins were detected by peroxidase conjugated rabbit antibodies (DAKO) against human IgG, IgA, or IgM using $o$-phenylenediamine (OPD) (Sigma) as substrate. The concentration of immunoglobulins was determined by referring to serial dilutions of standard serum (Behringwerke). The absorbance was recorded in a Titertek Multiscan spectrophotometer (Flow Laboratories).

DETECTION OF RHEUMATOID FACTORS

Serum samples, synovial fluids, and alkaline dissociated immune complexes were assayed for the presence of antirabbit Fc activity (RF activity) of the IgG, IgA, and IgM class. ${ }^{21}$ Microtitre plates were coated with human albumin and incubated with whole IgG or $\mathrm{Fab}_{2}$ fragments of rabbit IgG against human albumin. Serum or synovial fluid samples were diluted 1:1000, and the immune complex preparations were diluted 1:20. The binding of human antibodies was detected by peroxidase conjugated rabbit antibodies against human $\operatorname{IgG}, \operatorname{IgA}$, or IgM. The RF activity was recorded as the difference in optical density ( $\triangle \mathrm{OD})$ between the reaction with whole IgG and that with $\mathrm{Fab}_{2}$ fragments after 30 minutes incubation with OPD. The results were expressed as RF activity per microgram immunoglobulin of the respective isotype.

HUMAN ANTIBODIES AGAINST P27

Microtitre plates were coated with purified pso p27 antigen. The amount applied in each well corresponded to the amount obtained from $10 \mu \mathrm{g}$ of psoriatic scale. Serum samples and synovial fluids were diluted 1:1000, and the immune complex preparations were diluted 1:20. The binding of antipso p27 antibodies was detected by peroxidase conjugated rabbit antihuman $\operatorname{IgG}, \operatorname{IgA}$, or $\operatorname{IgM}$ 
antibodies (DAKO) using OPD as substrate. Uncoated wells served as negative controls. ${ }^{16}$ The colour development was stopped after four to six minutes for the $\mathrm{IgG}$ isotype, and after 30 minutes for the $\operatorname{IgA}$ and $\operatorname{IgM}$ isotypes. The results were expressed as anti-pso p27 activity per microgram immunoglobulin of the respective isotype.

\section{DETECTION OF P27 ANTIGEN}

Microtitre plates were coated with ascites fluid containing monoclonal anti-pso p27 antibodies 74G11D4 as described previously. ${ }^{19}$ The wells were incubated with alkaline dissociated immune complexes diluted 1:2. Biotinylated monoclonal anti-pso p27 antibodies 4-2D1H11 diluted 1:10 000, followed by peroxidase conjugated streptavidine (Bethesda Research Laboratories) diluted 1:500 were applied for the detection of bound antigens. OPD served as substrate, and the colour development was stopped after 30 minutes. Uncoated wells were used as negative controls.

\section{IMMUNOSORBENT CHROMATOGRAPHY} Human IgG (Kabi) was coupled to $\mathrm{CNBr}$ activated Sepharose 6MB (Pharmacia) using the procedure recommended by the manufacturer. Immunosorbent chromatography of alkaline dissociated immune complexes was performed in PBS T20. Unbound immune complex material was assayed for the presence of rheumatoid factor activity and anti-pso p27 activity as described above.

\section{Results}

RHEUMATOID FACTOR ACTIVITY

Serum samples from five patients with AS and five healthy persons, as well as synovial fluid from three patients with AS were assayed for the presence of free antirabbit $\mathrm{Fc}$ antibodies (RF activity). All samples were assayed in a dilution of 1:1000, and the isotype RF activity was recorded as $\triangle \mathrm{OD}$ of antibodies reacting with IgG and $\mathrm{Fab}_{2}$ fragments per microgram immunoglobulin of the respective isotype. Only insignificant amounts of free RF activity of the IgG, IgA, or IgM class were detected ( $\triangle \mathrm{OD}$ per $\mu \mathrm{g}$ immunoglobulin isotype $<0 \cdot 05$ ).

Immune complexes were isolated from the AS sera and the synovial fluids by isopycnic ultracentrifugation in sucrose gradients. The complexes were dissociated at high $\mathrm{pH}$, neutralised, and assayed for RF activity in a dilution of $1: 20$. Antibodies of the IgA or IgM class reacting with the $\mathrm{Fc}$ region of rabbit $\mathrm{IgG}$ could not be detected in any of the immune complex preparations. Considerable RF activity of the IgG class was observed in two of the patients (Nos 1 and 7). From patient No 1 we analysed both serum and synovial fluid immune complexes, and IgG rheumatoid factor activity was observed in both (Table 1). The RF activity of CICs from patients 2,4 , and 5 was also significantly등 positive when the mean RF activity in serum of healthy blood donors plus three standard deviations $(\triangle \mathrm{OD} / \mu \mathrm{g} \mathrm{IgG}=0.06)$ was used as cut off point. @

ANTIBODIES AGAINST PSO P27

The same serum samples and synovial fluids were analysed for the presence of free antibodies reacting $\vec{\omega}$ with pso p27. The samples were assayed in a dilutiono of $1: 1000$. Only insignificant amounts (OD $<0 \cdot 2 / \mu \mathrm{g} \widehat{\varrho}$ immunoglobulin isotype after 30 minutes incubation? with OPD) of IgG, IgA, or IgM antibodies reactingo with pso p27 were observed.

Both undissociated and alkaline dissociated im $-\infty$ mune complex preparations were then assayed for the presence of antibodies reacting with pso p27 $\vec{\longrightarrow}$ Significant anti-pso p27 activity was not observed using undissociated immune complexes. Table shows, however, that extensive amounts of $\operatorname{IgG}^{\text {P }}$ antibodies reacting with pso p27 were revealed aftero alkaline dissociation of the immune complexes in alpo samples studied. Moderate amounts of anti-pso p270 IgM antibodies were also detected, but no anti-psoß p27 IgA antibodies were observed. Fig. 1 shows IgGㅡㅡㅁ anti-pso p27 activity of serially diluted alkalineo dissociated CICs from patient No 1. The anti-psoD p27 activity recorded after 30 minutes' incubation with OPD of dissociated serum immune complexes from patient No 2 corresponded to $50 \cdot 63 / \mu \mathrm{g} \operatorname{IgG}$, while that of serum was $0.05 / \mu \mathrm{g} \mathrm{IgG}$, indicating that the anti-pso p27 IgG activity of dissociated immune complexes exceeded that of free serum IgG by factor of 1000 .

CICs from patient No 1 contained antibodies reacting with both the $\mathrm{Fc}$ region of rabbit IgG andB pso p27. We have shown that antigenic determinants

Table 1 IgG rheumatoid factor activity of alkaline dissociated immune complexes from sera and synovial fluids from patients with $A S$

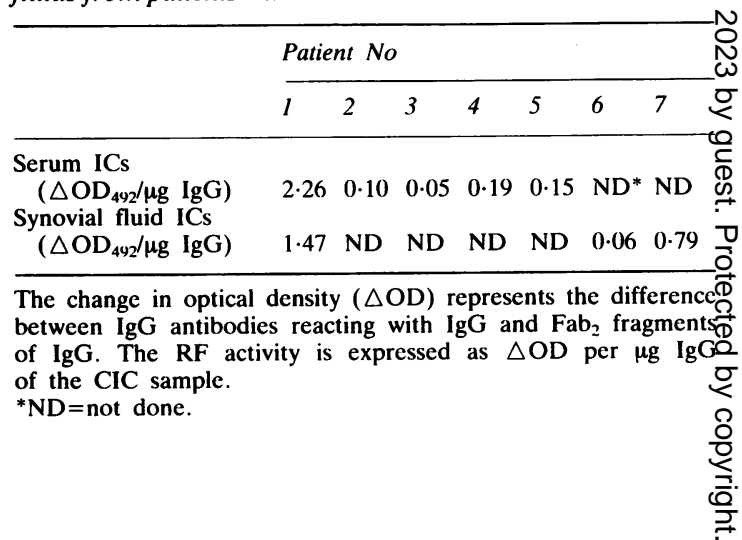


analysis, we identified, in a former study, antigens cross reacting with the envelope glycoprotein (gp70) of a psoriasis associated retrovirus-like particle in AS immune complexes. ${ }^{22}$ Previously, we analysed immune complexes from patients with psoriatic arthritis using ELISA techniques and showed that pso p27 participates in immune complex formation both in psoriatic scales and in CICs. ${ }^{16}$

The presence of RF activity, mainly of the IgG class, in sera from patients with AS has been reported, though it appears that such antibodies are either absent or present in relatively small amounts in most patients. ${ }^{23}{ }^{24}$ These observations were made using relatively crude techniques. In this report we applied a sensitive isotype-specific ELISA for the identification of $R^{21}$ Still, only insignificant amounts of free RF activity were observed in the serum samples or synovial fluids analysed. Some IgG RF activity was detected in CICs, indicating that although the presence of RF is not a prominent feature, RF may participate in immune complex formation in patients with AS.

Free antibodies reacting with pso p27 were also undetectable in any of the serum samples or synovial fluids examined, but extensive amounts were present in all immune complex preparations. The observations correspond to those seen in patients with psoriasis or psoriatic arthritis. ${ }^{16}$ The anti-pso p27 activity of the immune complex preparation of patient No 1 was reduced when the immune complexes were absorbed with IgG. In a previous paper we reported that pso p27 shares a common antigenic determinant with the Fc region of IgG. Thus the RF activity of the CICs from patient No 1 could be due to antibodies originally synthesised against an antigen related to pso p27.

In addition to the large amounts of anti-pso p27 antibodies, antigens reacting with monoclonal antibodies against pso p27 were observed in immune complex preparations from all of the serum samples studied, and from one of the synovial fluids. The antigens cross reacting with pso p27 are not IgG as the monoclonal antibodies applied do not react with IgG. Antigens related to pso p27 could not be detected in two of the synovial fluid immune complex preparations. Alkaline dissociated CICs, however, are applied for the detection of antigens cross reacting with pso p27. Thus the binding of antigen to the solid phase monoclonal anti-pso p27 antibodies occurs in the presence of CIC anti-pso p27 antibodies. Depending on the avidity as well as affinity of the CIC antibodies, they may compete with the solid phase monoclonal anti-pso p27 antibodies in the immobilisation of the antigen, and may also block the binding site for the biotinylated 'second' antibodies. This could explain the low. activity observed in two of the synovial flui immune complex preparations.

The identification of antibodies reacting with pse p27, as well as antigens cross reacting with pso p2\% in CICs, shows that antigens related to pso p2\% participate in immune complex formation in AS. I psoriasis pso p27 has been observed to participate iฉ̊ immune complex formation both locally in psoriatie scales and in CICs. ${ }^{16}$ In an immunofluorescence $\overrightarrow{0}$ analysis using antiserum against pso p2 $7^{17}$ we observed deposition of cross-reacting antigens iff synovial vessel walls closely resembling immune deposits. This observation further supports the suggestion that antigens related to pso p27 could bet important for the elicitation of inflammatory reaco tions in patients with AS.

This work was supported by grants from the Norwegian Society for? Fighting Cancer, and Dr Trygve Gythfeldt's Fund. $\mathrm{K} \AA$ is $\overrightarrow{\mathrm{a}}$ research fellow of the Norwegian Council for Science and the Humanities. The technical assistance of Miss H Lysvand and Mrs Carlsson, and the generous help offered by Dr $\emptyset$ Romberg ion providing the clinical specimens are gratefully acknowledged.

\section{References}

1 Cruickshank B. Pathology of ankylosing spondylitis. Clim Orthop 1971; 74: 44-58.

2 Teich N, Wyke J, Mak T, Bernstein A, Hardy W. Pathogenesis of retrovirus-induced disease. In: Weiss $\mathrm{R}$, Teich $\mathrm{N}$, Varmus $\mathrm{H}$ Coffin J, eds. RNA tumor viruses. New York: Cold Spring Harbor Laboratory, 1982: 785-998.

3 Crawford T B, Adams D A, Cheevers W P, Cork L C. Chronie arthritis in goats caused by a retrovirus. Science 1980; 20T 997-9.

4 Hang L M, Theofilopoulos A N, Dixon F J. A spontaneoug rheumatoid arthritis-like disease in MRL/1 mice. $J$ Exp Meळ 1982; 155: 1690-701.

5 Oldstone M B A, Dixon F J. Immune complex disease i⿱艹 chronic viral infections. J Exp Med 1971; 134 (suppl): 32-40\$

6 Burger D, Sriranganathan N, McDonald T L, Gorham J R Isolation of virus and antibody containing immune complexes from mink with Aleutian disease by affinity chromatography 8 equine complement C1q. Am J Vet Res 1983; 44: 86-90.

7 Snyder H W Jr, Jones F R, Day N K, Hardy W J Jr. Isolatiog and characterization of circulating feline leukemia viruse immune complexes from plasma of persistently infected pet cats removed by ex vivo immunosorption. J Immunol 1982; 128 2726-30.

8 Wands J R, Mann E, Alpert E, Isselbacher $\mathrm{K}$ J. Th $\mathfrak{\mathcal { G }}$ pathogenesis of arthritis associated with acute hepatitis- $\mathrm{B}$ surface antigen-positive hepatitis. J Clin Invest 1975; 55: 930-60

9 Utsinger P D, Zvaifler N J, Weiner S B. Etiology. In: Utsinget P D, Zvaifler N J, Ehrlich G E, eds. Rheumatoid arthritif Philadelphia: Lippincott, 1985: 21-48.

10 Moll J M H, Haslock I, Macrae I F, Wright V. Associatioff between ankylosing spondylitis, psoriatic arthritis, Reiter disease, the intestinal arthropathies, and Behçet's syndromen Medicine (Baltimore) 1974; 53: 343-64.

11 Møller P, Berg K. Family studies in Bechterew's syndromg (ankylosing spondylitis). III. Genetics. Clin Genet 1983; 24 73-89.

12 Møller P, Vinje O, Kåss E, Berg K. The distribution of clinicå findings in Bechterew's syndrome (ankylosing spondylitisf suggests distinct genetic subgroups. Clin Genet 1982; 22: 151-

13 Eastmond C J, Woodrow J C. The HLA system and the 
arthropathics associated with psoriasis. Ann Rheum Dis 1977: 36: $112-20$.

14 Iversen O-J, Dalen A B. Urine proteins cross-reacting with antiserum against virus-like particles from cultured psoriatic epithelial cells. Acta Pathol Microbiol Immunol Scand /B/ 1983; 91: 343-9.

15 Iversen O-J. Isolation of virus-like particles in urine from a psoriatic patient. Acta Pathol Microbiol Immunol Scand $|B|$ 1983; 91: 407-12.

16 Iversen O-J, Rødahl E. The major internal protein, p27, of a retrovirus-like particle participates in immune complex formation in psoriasis. Arch Virol 1985; 86: 37-45.

17 Rødahl E. Iversen O-J. Antigens related to the major internal protein, p27, of a psoriasis associated retrovirus-like particle are expressed in patients with chronic arthritis. Ann Rheum Dis 1985; 44: 761-5.

18 Rødahl E, Iversen O-J, Dalen A B. Preparative isolation of immune complexes from serum by sucrose gradient ultracentrifugation. Scand J Immunol 1984; 20: 21-6.

19 Åsbakk K, Iversen O-J. Monoclonal antibodies against the major internal protein, p27, of a psoriasis-associated retroviruslike particle. Scand J Immunol (in press).

20 Stähli C, Miggiano V. Stocker J. Staehelin T, Häring P. Takács B. Distinction of epitopes by monoclonal antibodies. Methods Enzymol 1983: 92: 242-53.

21 Åsbakk K. Iversen O-J. Rheumatoid factors in psoriatic lesions, serum and circulating immune complexes detected by an isotype-specific ELISA. Acta Pathol Microbiol Immunol Scand [C] 1987; 95: 161-6.

22 Rødahl E, Iversen O-J. Analysis of circulating immune complexes from patients with ankylosing spondylitis by gel electrophoresis and immunoblotting using antiserum against a psoriasis associated retrovirus-like particle. Ann Rheum Dis 1986: 45: 892-8.

23 Arana R M. de la Vega M T. Porrini A, Morteo O G. Antiglobulins in ankylosing spondylitis. $J$ Rheumatol 1975; 2: 303-7.

24 Duquesnoy B, Santoro F. Wattre P. Delcambre B. Failure to find Clq-binding material and anti-IgG antibodies in ankylosing spondylitis. Ann Rheum Dis 1979: 38: 449-52. 